\title{
MAPK Establishes a Molecular Context That Defines Effective Training Patterns for Long-Term Memory Formation
}

\author{
Gary T. Philips, Xiaojing Ye, Ashley M. Kopec, and Thomas J. Carew \\ Center for Neural Science, New York University, New York, New York 10003
}

\begin{abstract}
Although the importance of spaced training trials in the formation of long-term memory (LTM) is widely appreciated, surprisingly little is known about the molecular mechanisms that support interactions between individual trials. The intertrial dynamics of ERK/MAPK activation have recently been correlated with effective training patterns for LTM. However, whether and how MAPK is required to mediate intertrial interactions remains unknown. Using a novel two-trial training pattern which induces LTM in Aplysia, we show that the first of two training trials recruits delayed protein synthesis-dependent nuclear MAPK activity that establishes a unique molecular context involving the recruitment of CREB kinase and $A p C / E B P$ and is an essential intertrial signaling mechanism for LTM induction. These findings provide the first demonstration of a requirement for MAPK in the intertrial interactions during memory formation and suggest that the kinetics of MAPK activation following individual experiences determines effective training intervals for LTM formation.
\end{abstract}

\section{Introduction}

The formation of lasting memories significantly benefits from the temporal distribution of study sessions with intervening rest intervals (spaced versus massed training; Ebbinghaus, 1885; Cepeda et al., 2006). However, surprisingly little is known about the dynamic signaling that is important for the integration of temporally spaced trials during long-term memory (LTM) formation. In several systems, peak extracellular signal-regulated protein kinase/mitogen-activated protein kinase (MAPK) activation following individual training trials has recently been correlated with optimal intertrial intervals (ITIs) for the induction of long-term synaptic plasticity (Ajay and Bhalla, 2004) and memory (Philips et al., 2007; Pagani et al., 2009). Conversely, learning deficits in humans have been associated with a dysfunction of MAPK activation (Tidyman and Rauen, 2009). However, despite strong correlative evidence, a definitive requirement of MAPK activity in intertrial interactions during memory formation remains untested.

In the model system Aplysia californica, memory for sensitization, a generalized arousal induced by training shock, is sensitive to both the amount and pattern of training (Pinsker et al., 1973; Sutton et al., 2002). We recently reported a novel two-trial training pattern for the induction of LTM for sensitization of the

\footnotetext{
Received Dec. 3, 2012; revised March 19, 2013; accepted March 20, 2013.

Author contributions: G.T.P. and T.J.C. designed research; G.T.P., X.Y., and A.M.K. performed research; G.T.P., X.Y., and A.M.K. analyzed data; and G.T.P. and T.J.C. wrote the paper.

This work was supported by NIMH Grants R01MH041083 and R01MH094792 to T.J.C., and R01MH081151 to T.J.C. and K. C. Martin. We thank both present and former members of the Carew laboratory and Dr. Marcelo A. Wood and Dr. John F. Guzowski for thoughtful advice during the early stages of this work.

The authors declare no competing financial interests.

Correspondence should be addressed to Thomas J. Carew, Office of the Dean of FAS, 5 Washington Square North, 1st Floor, New York, NY 10003-6667. E-mail: tcarew@nyu.edu.

DOI:10.1523/JNEUROSCI.5561-12.2013

Copyright $\odot 2013$ the authors $\quad 0270-6474 / 13 / 337565-09 \$ 15.00 / 0$
}

tail-elicited siphon withdrawal reflex (T-SWR) of Aplysia and identified MAPK signaling as a potential mechanism of intertrial signaling during LTM formation (Philips et al., 2007). Importantly, the two training trials had to be critically spaced: $45 \mathrm{~min}$ spacing intervals, but not 15 min or $1 \mathrm{~h}$ intervals, successfully induced LTM comparable to that induced with four spaced trials (ITI $=15 \mathrm{~min}$ ). MAPK activation in tail sensory neurons (SNs) of the T-SWR circuit reliably correlated with the narrow two-trial training interval: MAPK is activated at $45 \mathrm{~min}$ following Trial 1 , but is not activated at $15 \mathrm{~min}$ or at $1 \mathrm{~h}$. Given that a single training trial is not sufficient for LTM, we hypothesized that the MAPK activated by Trial 1 is a critical factor in determining the effective intertrial interaction during two-trial LTM induction (Philips et al., 2007).

To test this hypothesis, we asked the following questions: first, what signaling determines the restricted activation of Trial 1 MAPK? Second, what signals are downstream of MAPK that create a unique temporal context in tail SNs? Finally, can we directly establish the behavioral relevance of Trial 1 MAPK activation? We found that a brief application of the neuromodulator serotonin $(5 \mathrm{HT})$, which is released onto SNs immediately after training shock (Marinesco and Carew, 2002), was sufficient to activate MAPK in the same temporal window as observed during behavioral training of the intact animal. Surprisingly, the transient serotonin-induced MAPK activation had four critical features: (1) it required protein synthesis, (2) it translocated to the nucleus of tail SNs, (3) it activated the CREB kinase p90rsk, and (4) it increased transcription of the CREB target, $A p C / E B P$. Finally, targeted disruption of the MAPK-dependent "molecular context" established by training Trial 1 prevented two-trial LTM formation. These findings demonstrate an essential requirement of MAPK in mediating intertrial signaling during LTM formation, and highlight the recruitment of both CREB signaling and 
gene expression within rest intervals in spaced training as potentially important MAPK-dependent signaling mechanisms that determine effective training intervals for memory formation.

\section{Materials and Methods}

Behavioral procedures. Under anesthesia, Aplysia (weighing 250-400 g) were surgically reduced to provide two T-TWR preparations consisting of the tail hemi-segment, ipsilateral body wall and ipsilateral pleural and pedal ganglia of the CNS interconnected by the tail (P9) nerve (Fig. $1 a$; Philips et al., 2011). The T-TWR was initiated by a single $0.5 \mathrm{~s}$ electrical stimulus to the tail test site $(2-10 \mathrm{~mA})$. Baseline responding (measured through a strain gauge connected to the tail) was determined through three pretests, intertest interval (ITI) $=15 \mathrm{~min}$. In Figure 1, preparations were trained with two shocks ( $1.5 \mathrm{~s} 100 \mathrm{~mA})$ to the posterior body wall through a handheld electrode or were untrained. In Figure 5, the requirement of MAPK in the intertrial interactions during two-trial LTM induction was tested using the MEK inhibitor U0126 (20 $\mu \mathrm{M}$ in DMSO, Tocris Bioscience). U0126, or the inactive analog U0124 (20 $\mu \mathrm{M}$, Tocris Bioscience), was applied to the CNS chamber of behaving preparations after the second pretest. U0126/ U0124 had no effect on baseline responding as assessed through comparison with a third pretest $30 \mathrm{~min}$ into drug incubation. Drug was washed out ( $5 \mathrm{ml} \mathrm{ASW} / \mathrm{min}$ ) beginning $15 \mathrm{~min}$ post-training Trial 1 . Trial 2 was given at the $45 \mathrm{~min}$ intershock interval (30 min into drug washout). Post-tests were administered beginning $18-22 \mathrm{~h}$ post-training to assess LTM ( 3 post-tests, ITI $=15 \mathrm{~min}$ ).

$5 H T$-induced MAPK activation. MAPK activation in SNs of the VC cluster was examined in pleural-pedal ganglia isolated from anesthetized animals (each animal provided two pleural-pedal ganglia pairs). Ganglia recovered in ASW for 1.5-2 h. Molecular experiments were conducted using a counterbalanced within animal design: one ganglia pair received control treatment (ASW) and the other pair was exposed to $50 \mu \mathrm{M} 5 \mathrm{HT}$ for $5 \mathrm{~min}$, followed by rapid washout with ASW. SN cell bodies were collected at 15, 45, or 60 min post-5HT treatment onset. Emetine (100 $\mu \mathrm{M}$ in ASW; Sutton et al., 2001), U0126 (20 $\mu \mathrm{M}$ in DMSO; Sharma et al., 2003) and Actinomycin D (40 $\mu \mathrm{M}$ in ASW; Sherff and Carew, 2004) were introduced at working concentration through an initial $7 \times$ dish volume exchange.

Western blot analysis. Lysates of tail SN cell bodies were prepared and analyzed by Western blot analysis as previously described (Sharma et al., 2003; Philips et al., 2007). The active population of MAPK in each sample was detected by probing first for phosphorylated MAPK (P-MAPK; Thr202/Tyr204, Cell Signaling Technology) and then reprobing stripped membranes for total MAPK (T-MAPK; p44/p42, Cell Signaling Technology). MAPK activation was determined using a semiquantitative analysis of the P-MAPK and T-MAPK signal in each sample and comparing P-MAPK/T-MAPK ratios obtained from 5HT-treated and control (ASW-treated) ganglia of the same animal. p90rsk phosphorylation was detected using a phospho-specific antibody (p90rsk-ser380, \#9341, Cell Signaling Technology) and normalization of this signal to total $\beta$ tubulin (\#2146, Cell Signaling Technology). Initial characterization of the p90rsk antibody in Aplysia recognized a single band at $\sim 90 \mathrm{kDa}$ that was phosphorylated downstream of MAPK (see Fig. $4 a$; Dalby et al., 1998; Romeo et al., 2012). p90rsk activation was described by comparing values obtained from 5HT- and ASW-treated ganglia.

Whole-mount immunofluorescent staining. Pleural-pedal ganglia were fixed ( $4 \%$ formaldehyde, $30 \%$ sucrose, $30 \mathrm{~mm} \mathrm{NaF}, 3 \mathrm{~mm} \mathrm{NaOv}$ in PBS) at $45 \mathrm{~min}$ after a $5 \mathrm{~min} 50 \mu \mathrm{M} 5 \mathrm{HT}$ treatment for $30 \mathrm{~min}$ at room temperature, then for $1 \mathrm{~h}$ at $4^{\circ} \mathrm{C}$. Ganglia were permeabilized (4\% Triton $\mathrm{X}-100,1 \mathrm{~h}$ ) and then quenched ( $1 \mathrm{~m}$ Glycine, $30 \mathrm{~min})$. Nonspecific bind- ing sites were blocked with $10 \%$ normal goat serum (diluted in $0.5 \%$ Triton X-100, 0.05\% Tween-20, $30 \mathrm{~mm} \mathrm{NaF}, 3 \mathrm{~mm} \mathrm{NaOv}$ in PBS) for $1 \mathrm{~h}$. Afterward, phospho- (Cell Signaling Technology, mouse, 1:200) or totalMAPK antibody (Cell Signaling Technology, rabbit, 1:100) and H2A.Z antibody (Cell Signaling Technology, rabbit, 1:200) were incubated with the ganglia for $2.5 \mathrm{~d}$ at $4^{\circ} \mathrm{C}$. Secondary antibodies were applied at 1:200 $2 \%$ goat serum for $1 \mathrm{~h}$. Samples were preserved using SlowFade Gold Antifade Reagent with DAPI (Invitrogen). Confocal images through SN cell bodies were captured using the LSM 510M Confocal Microscope (Zeiss) and quantified using ImageJ by an individual blind to treatment history. SN cell bodies were identified by their location in the pleural VC cluster and their distinctive small size, ranging from 30 to $80 \mu \mathrm{m}$ in diameter (Walters et al., 1983b; Walters et al., 2004). Cell bodies and nuclei (using either the H2A.Z or DAPI signal as a mask) of pleural sensory neurons were manually outlined. The cytoplasm was defined by subtracting the nuclear mask from each cell body mask. Data are presented as a ratio of the nucleus to cytoplasm mean pixel intensities.

$c D N A$ synthesis and $q R T-P C R$. Pleural sensory clusters were excised at 45 min after 5HT treatment and homogenized in resuspension buffer (Invitrogen). The homogenate was split to (1) synthesize cDNA (CellsDirect, Invitrogen) and (2) to confirm MAPK activation within the same sample by Western blot. Before qRT-PCR, cDNA samples were incubated with $1 \mu \mathrm{l}$ RNase at $37^{\circ} \mathrm{C}$ for $20 \mathrm{~min}$ to remove any residual RNA. They were then amplified $\left(95^{\circ} \mathrm{C} 10 \mathrm{~s}, 58^{\circ} \mathrm{C} 20 \mathrm{~s}, 72^{\circ} \mathrm{C} 30 \mathrm{~s}\right)$ in a LightCycler 480 (Roche) with SYBR Green dye. The primers used in the reaction were C/EBP-F (5' $5^{\prime}$ TACT CTCAACCTTCCCTCAAGC-3') and C/EBP-R (5' -TGACAAATGAACAA AATGCACA- $3^{\prime}$ ). As a control, the amount of the ribosomal subunit S4 cDNA was detected in the same samples using primer pair S4-F ( $5^{\prime}$-GACC CTCTGGTGAAGGTGAA- $3^{\prime}$ ) and S4-R (5'-TGGACAGCTTCACACCTT TG-3'). For quantification, the amount of ApC/EBP in each sample was first normalized to S4. Data are presented as a ratio of normalized ApC/EBP levels in the 5HT-treated side to that in the mock-treated side (C/EBP induction).

Statistical analysis. Where appropriate, a one-way ANOVA was run and is reported in the main text. Subsequent planned between group comparisons were made using a $t$ test for independent means. The induction of LTM for sensitization in trained and untrained groups was additionally determined using a paired sample $t$ test of the average baseline and $18-22 \mathrm{~h}$ responses. A within animal design was used in the molecular studies. Control and experimental values were compared using the paired samples $t$ test. Due to a non-normal distribution, the Wilcoxon's matched-pairs signed rank test was used for analyzing within-group $C / E B P$ induction. All analyses were conducted using Prism Graphpad 5. Outliers, identified as values greater than 2 SDs from the mean (a common winsorization rule; Dixon and Tukey, 1968), are indicated in the 
paper and resulted in the removal of 2 of 200 data points (1\%). Unless otherwise indicated, all data are expressed as mean \pm SEM.

\section{Results}

Two-trial LTM induction in the tail-elicited tail withdrawal reflex of Aplysia has a narrow temporal window and is correlated with MAPK activation in tail SNs

We previously reported the induction of two-trial LTM in a reduced behavioral preparation of the tail-elicited tail withdrawal reflex (T-TWR; Philips et al., 2011), a significant component of which is expressed through a well characterized central tail SNmotor neuron (MN) synapse (Walters et al., 1983a; Philips et al., 2011). Here we tested the hypothesis that much of the pattern sensitivity previously observed during two-trial sensitization of the tail-elicited siphon withdrawal reflex (T-SWR; Philips et al., 2007) is mediated by the tail SNs, which provide the input pathway for both reflexes. If correct, these same SNs should impart similar pattern sensitivity during two-trial memory formation for sensitization of the T-TWR (Philips et al., 2011). T-TWR preparations were trained with two shocks $(10 \mathrm{~mA}, 1.5 \mathrm{~s})$ spaced by (1) $15 \min (2 \times 15),(2) 45 \min (2 \times 45),(3) 60 \min (2 \times 60)$, or (4) they were untrained (Fig. 1). A one-way ANOVA comparing the group scores revealed a significant effect of training on the amplitude of the T-TWR at $18-22 \mathrm{~h}$ post-training $\left(F_{(3,20)}=\right.$ $6.738, p=0.0025$; Fig. $1 b$ ). Subsequent between group comparisons of trained versus untrained animals confirmed our previous report (Philips et al., 2011) of a significant enhancement in the T-TWR response amplitude (LTM) in the group which received $2 \times 45$ training $(n=5,169 \pm 20 \%)$, compared with untrained controls $(n=5,86 \pm 12 \%, p=0.0072)$. The T-TWR amplitude of preparations trained at either $2 \times 15(n=9,82 \pm 10 \%)$ or at $2 \times 60(n=5,84 \pm 24 \%)$ was not different from control levels ( $p=0.76$ and 0.92 , respectively). In sum, the T-TWR shares with the T-SWR (Philips et al., 2007) a narrow two-trial training interval at $45 \mathrm{~min}$ for LTM induction.

The narrow two-trial training interval for sensitization of the T-SWR is accompanied by the temporally restricted activation of MAPK in tail SN cell bodies at 45 min following the initial training shock (Philips et al., 2007). Consistent with this earlier observation, we found that during sensitization of the T-TWR, a single training shock results in the activation of MAPK in tail SNs at 45 $\min (n=7,157 \pm 15 \%$ untrained phosphorylated-MAPK/totalMAPK ratio, $p=0.0087$ paired $t$ test, see Fig. $5 a$, ASW). Collectively, the data support the hypothesis that much of the training pattern sensitivity lies within the tail SNs which are presynaptic to both central reflex circuits, and identifies a unique opportunity to study the mechanisms underlying the temporal specificity of the two-trial training interval in the T-TWR reflex where the pre- and post-synaptic elements which contribute to the reflex are well understood.

\section{The narrow temporal window of MAPK activation by behavioral training is also observed in vitro in response to exogenous 5HT application}

To determine the mechanisms which underlie Trial 1 MAPK activation, we next focused on the signaling downstream of a single training shock. A single training shock results in the immediate release of the neuromodulator, $5 \mathrm{HT}$, onto tail SN cell bodies and sensorimotor synapses (Marinesco and Carew, 2002; Philips et al., 2011), and brief (5 min) exposure of 5HT to the CNS can serve as a proxy for shock in (1) transiently strengthening tail SN-MN synapses (Brunelli et al., 1976; Walters et al., 1983a; Mauelshagen et al., 1996) and (2) sensitizing the T-TWR (Wal-
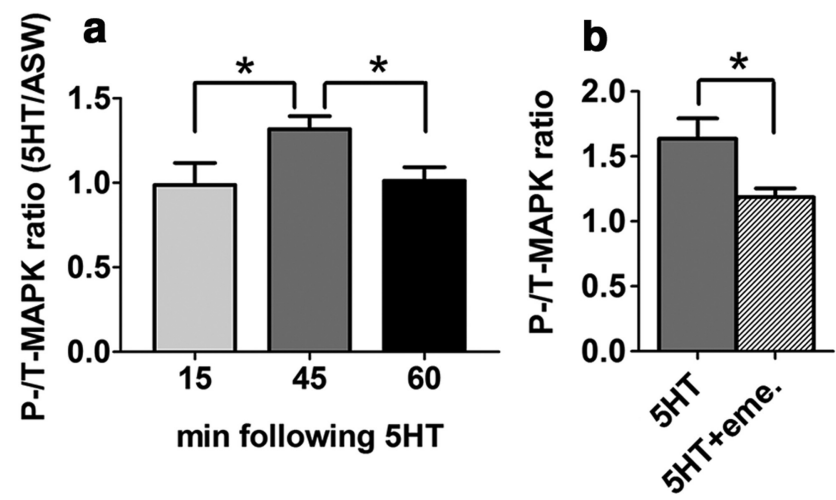

Figure 2. Serotonin can serve as a proxy for training shock in the restricted temporal activation of protein synthesis-dependent MAPK. $\boldsymbol{a}, \mathrm{A} 5 \mathrm{~min} 5 \mathrm{HT}$ exposure to the isolated pleuralpedal ganglia induced significant MAPK activation in tail SNs at 45 min compared with paired ASW-treated control ganglia. No activation was observed at $15 \mathrm{~min}$ or at $1 \mathrm{~h}$ following the same treatment. $\boldsymbol{b}$, Exposure to the protein synthesis inhibitor emetine (eme.) for 30 min before 5 HT treatment prevented the $5 \mathrm{HT}$-induced MAPK activation at $45 \mathrm{~min}$.

ters et al., 1983a; Philips et al., 2011). Additionally, repeated training shocks or 5HT exposures give rise to sustained posttraining MAPK activation in tail SNs (Sharma et al., 2003). Given these collective findings, we tested the prediction that $5 \mathrm{HT}$ signaling was upstream of Trial 1 MAPK activation. Pleural-pedal ganglia pairs (containing the tail SNs and $\mathrm{SN}-\mathrm{MN}$ synapses) were isolated and treated with either a single 5 min application of 50 $\mu \mathrm{M} 5 \mathrm{HT}$ or vehicle (ASW). At 15, 45, or $60 \mathrm{~min}$ post-onset of the treatment, tail SN cell bodies were harvested from the pleural ganglion and analyzed by Western blot for MAPK activation (Philips et al., 2007). An ANOVA of P-MAPK/T-MAPK ratios across the three groups indicated a temporally restricted activation of MAPK following 5HT treatment $\left(F_{(2,24)}=4.459, p=\right.$ 0.0226; Fig. 2a). Subsequent post hoc analyses revealed that MAPK activation at $45 \mathrm{~min}$ was significantly elevated above levels observed at 15 and 60 min following 5HT exposure (LSD, $p=$ 0.019 and $p=0.030$, respectively). Within-group analyses also identified significant activation of MAPK above control levels at $45 \min (n=11,1$ outlier, $1.3 \pm 0.08 p=0.0007$, paired $t$ test $)$, but not at $15 \min (n=8,0.99 \pm 0.13, p=0.683)$ or $60 \min (n=8,1$ outlier, $1.0 \pm 0.08, p=0.627)$. 5HT-induced MAPK activation required MEK activity, since activation at 45 min was completely disrupted in the presence of the MEK inhibitor, U0126 $(n=5$, $92 \pm 10 \% 5 \mathrm{HT}$-/ASW-treated, $p=0.434$ paired $t$ test, data not shown). The similar temporal profile of MAPK activation following training shock (Philips et al., 2007) and 5HT treatment strongly supports the hypothesis that MAPK is activated by the 5HT released during the initial training shock (Trial 1).

\section{The delayed temporal window of Trial 1 MAPK activation requires translation but not transcription}

Having established that 5HT treatment induces the same temporal profile of MAPK activation as observed following training shock, we next explored the mechanisms of the delayed activation. We have previously shown that a sustained (1-3 h) MAPK activation develops in tail SNs following spaced training (4 or 5 spaced training shocks or pulses of 5HT; Sharma et al., 2003) and is necessary for LTM formation (Shobe et al., 2005). Induction of the 5HT-dependent sustained MAPK activity requires protein synthesis, but not new gene transcription (Hu et al., 2004, 2006). To examine the mechanistic correspondence between repeated trial sustained MAPK and Trial 1 MAPK, we next asked whether 
the delayed and transient activation of MAPK by $5 \mathrm{HT}$ also requires new protein synthesis. Isolated pleural-pedal ganglia were exposed to $5 \mathrm{HT}$ in the presence or absence of the protein synthesis inhibitor emetine $(100 \mu \mathrm{M})$. Emetine treatment had no effect on basal levels of phosphorylated MAPK $(n=8,1.13 \pm 0.21$ P-MAPK/ T-MAPK ratio ASW/ASW-emetine, $p=$ 0.909, data not shown). However, emetine exposure to the CNS for $30 \mathrm{~min}$ before $5 \mathrm{HT}$ application completely blocked 5HTinduced delayed MAPK activation $(n=19$, 5HT: $1.64 \pm 0.16$ P-MAPK/T-MAPK ratio, 5HT-emetine: $1.19 \pm 0.07, p=0.003$ paired $t$ test, Fig. $2 b$ ). This surprising requirement for transient MAPK activation after a single training trial implies that protein synthesis is engaged much earlier in training than previously appreciated. Similar to repeated trial MAPK activation (Sharma et al., 2003), treatment with the transcriptional inhibitor Actinomycin D (50 $\mu \mathrm{g} / \mathrm{ml})$ for $1 \mathrm{~h}$ before ASW or $5 \mathrm{HT}$ exposure did not disrupt Trial 1 MAPK activation $(n=$ 12, 5HT/ASW: $1.52 \pm 0.23, p=0.029)$. Collectively these data show that single-trial MAPK activation at $45 \mathrm{~min}$ requires new protein synthesis, but not transcription. The dependence of Trial 1 MAPK activation on protein synthesis may be sufficient to account for the delay in its activation and therefore also sufficient to account for the timing of the LTM permissive two-trial training interval.

\section{Single-trial 5HT exposure drives the nuclear translocation of MAPK}

MAPK is significantly phosphorylated in isolated $\mathrm{SN}$ cell bodies at $45 \mathrm{~min}$ following a single training trial, but not at $15 \mathrm{~min}$ or at $1 \mathrm{~h}$. This phosphorylation could, in principle, support the translocation of MAPK to the nucleus to participate in LTM induction (Turjanski et al., 2007). To explore the subcellular location (nuclear vs cytoplasmic) of activated MAPK at $45 \mathrm{~min}$, we next examined pleural-pedal ganglia pairs $(n=8)$ treated with $5 \mathrm{HT}$ or ASW, fixed at $45 \mathrm{~min}$ and immunostained for P-MAPK. DAPI was used to label nuclei. Tail SN cell bodies were then imaged by confocal microscopy (Fig. 3). 5HT significantly increased the nuclear:cytoplasmic ratio of P-MAPK in tail SNs at $45 \mathrm{~min}$ (5HT: mean pixel intensity \pm SEM, $0.84 \pm 0.03$, ASW: $0.65 \pm 0.03, p=$ 0.038; Fig. 3). Cytoplasmic levels of P-MAPK were also increased by $5 \mathrm{HT}$ treatment $(5 \mathrm{HT}: 86 \pm 3$ mean pixel intensity, ASW: $52 \pm$ $2, p<0.001)$. Additionally, we examined T-MAPK immunoreactivity in pleural-pedal ganglia treated with either 5HT or ASW. As with P-MAPK labeling, we found a significant increase in the nuclear:cytoplasmic ratio of T-MAPK immunostaining in tail SN somata at $45 \mathrm{~min}$ post $5 \mathrm{HT}$ treatment $(n=6,5 \mathrm{HT}: 0.66 \pm 0.02$, ASW: $0.53 \pm 0.02, p=0.034$, data not shown). Collectively, these data support a model in which a single training trial, via the release of 5HT, recruits the temporally restricted nuclear translocation of activated MAPK in tail SNs at $45 \mathrm{~min}$.

Trial 1-induced MAPK transiently activates the CREB kinase p90rsk and increases transcript levels of the immediate early gene $A p C / E B P$

The phosphorylation and subsequent nuclear translocation of MAPK is thought to be an essential step in the activation of the transcription factor CREB, and CREB-dependent immediate early gene transcription necessary for LTM induction (Yin et al.,
1994; Guzowski and McGaugh, 1997; Sharma and Carew, 2004; Lee et al., 2008). MAPK is known to activate CREB indirectly through the cytoplasm-localized kinase p90rsk (RSK1/2; Arthur et al., 2004), and p90rsk phosphorylation (activation) is correlated with MAPK activation during learning (Sindreu et al., 2007). We explored the potential recruitment of p90rsk following $5 \mathrm{HT}$ treatment and found that its phosphorylation is significantly increased above control levels in SNs at 45 min following a single 5 min 5 HT treatment $(n=14,5 \mathrm{HT}: 1.1 \pm 0.08$ phosphorylated p90rsk/ $\beta$ tubulin ratio; ASW: $0.8 \pm 0.09, p=0.001$ paired $t$ test; Fig. 4a). Moreover, 5HT-induced p-p90rsk was completely disrupted by U0126, demonstrating that it is downstream of MAPK activity (U0126: $n=6,0.86 \pm 0.07$ 5HT/ASW ratio, $p=$ 0.063 , U0124: $n=4,2.1 \pm 0.8, p=0.04)$. Finally, the activation of p90rsk was transient and was no longer observed at $1 \mathrm{~h}$ following $5 \mathrm{HT}$ treatment $(n=7,1.3 \pm 0.45 \mathrm{HT} / \mathrm{ASW}$ ratio, $p=0.77$ paired $t$ test, NS, data not shown). These data show that Trial 1 MAPK signals through a transient activation of the CREB kinase, p90rsk, at the 45 min two-trial training window.

We next explored the potential impact of MAPK-dependent p90rsk activation and nuclear MAPK activity, which can promote CREB-mediated transcription, by examining a primary downstream target of CREB, the immediate early gene $A p C / E B P$. $\mathrm{C} / \mathrm{EBP}$ is critical for long-term memory formation in Aplysia and other systems (Alberini et al., 1994; Taubenfeld et al., 2001). Using quantitative RT-PCR we examined whether transcript levels of $A p C / E B P$ were differentially affected in the permissive time window 45 min following a single $5 \mathrm{HT}$ treatment. We found that $A p C / E B P$ message levels were significantly increased at $45 \mathrm{~min}$ after $5 \mathrm{HT}$ relative to a control, the $S 4$ ribosomal subunit $(n=10$, median $\pm \mathrm{IQR}, 1.6 \pm 2.7, \mathrm{~W}=7, p=0.04$, Wilcoxon matchedpairs signed rank test; Figure $4 b$ ). In a parallel analysis of the same samples, we confirmed MAPK activation $(p=0.001)$. ApC/EBP induction required MAPK activation since it was significantly disrupted by U0126 treatment (U0126: $n=8$, median \pm IQR, $0.95 \pm 0.4$ control levels, $\mathrm{W}=10, p=0.55$, U0124: $n=7,1.25 \pm$ $1.3, \mathrm{~W}=-28, p=0.02)$. Finally, $A p C / E B P$ induction was not observed at $1 \mathrm{~h}$ following $5 \mathrm{HT}$ treatment $(n=6$, median $\pm \mathrm{IQR}$, $1.0 \pm 1.25$ control levels, $\mathrm{W}=-1, p>0.99$, data not shown). Thus, MAPK-dependent $A p C / E B P$ induction is observed during the 45 min training window, but this induction is transient and is not observed at $1 \mathrm{~h}$, in the absence of MAPK activation. Collectively, these data lend strong support to the hypothesis that 

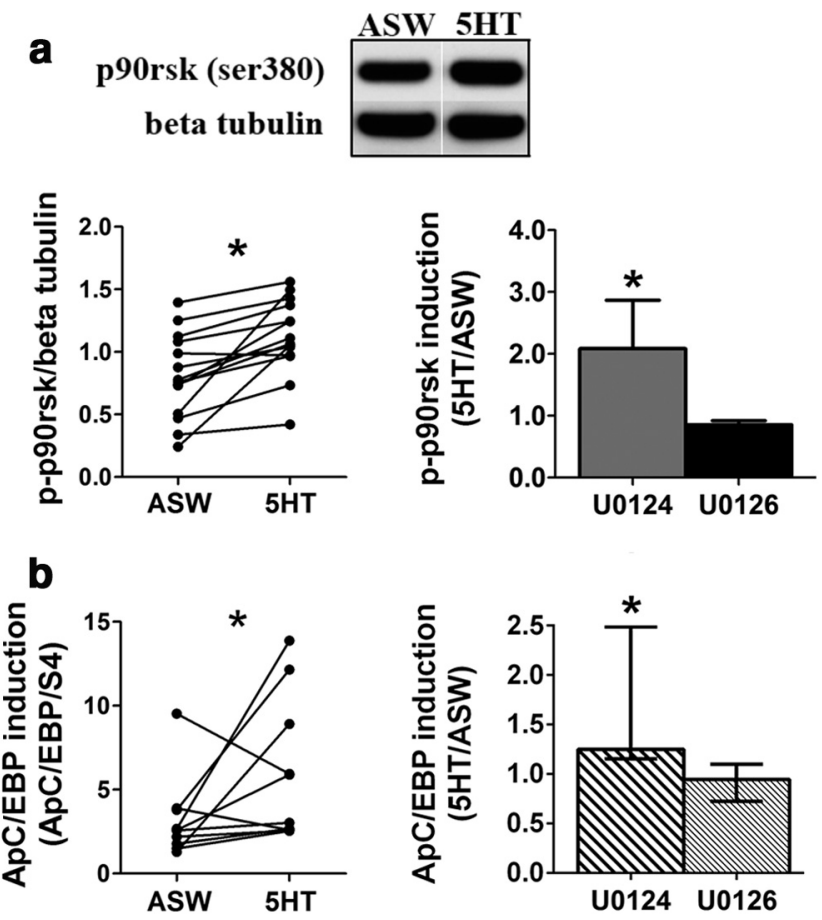

Figure 4. Trial 1 MAPK activates the CREB kinase p90rsk and increases transcription of the immediate early gene $A p C / E B P . \boldsymbol{a}$, Top, Representative image of phosphorylated p90rsk (pp90rsk) levels in ASW- and 5HT-treated SN clusters at 45 min . Bottom, Summary analysis of normalized $p$-p90rsk levels observed in ASW- and 5HT-treated SNs. Exposure to the MEK inhibitor, U0126, disrupted the observed 5HT-induced increase in p-p90rsk. Treatment with the inactive analog, $\mathrm{U} 0124$, had no significant effect. Data in histograms are presented as mean \pm SEM. $\boldsymbol{b}$, qRT-PCR was performed to determine transcript levels of the immediate early gene $A p C / E B P$ and the ribosomal $S 4$ subunit. Levels of $A p C / E B P$ (normalized to levels of $S 4$ ) were increased by 5 HT. U0126, but not U0124, disrupted the 5 HT-induced ApC/EBP induction. Asterisks indicate significant within-group activation. Data in histograms are presented as median \pm interquartile range.

MAPK is upstream of the transient induction of CREB-mediated gene expression following a single training trial.

Trial 1-induced MAPK activity is required for two-trial LTM While peak levels of activated MAPK have been correlated with optimal training intervals for the induction of long-term plasticity and memory during spaced training (Ajay and Bhalla, 2004; Philips et al., 2007; Pagani et al., 2009), the essential requirement for MAPK signaling in the same intertrial interactions during plasticity and memory formation has not yet been demonstrated. We have previously shown that U0126 (but not the inactive analog U0124) disrupts the formation of repeated-trial LTM in a reduced behaving preparation of the T-SWR (Sharma et al., 2003). Using a similar treatment strategy (CNS exposure to drug before, during and for $1 \mathrm{~h}$ after training), we first established that MAPK activation was required for the induction of two-trial LTM (U0124: $n=4,204 \pm 51 \%$ baseline T-TWR amplitude, U0126: $n=4,68 \pm 9 \%$ baseline T-TWR amplitude, $p=0.04$ unpaired $t$ test, data not shown). This result confirms that MAPK activity during or after training (or both) is required for two-trial LTM.

Having found that Trial 1 MAPK translocates to the nucleus and promotes CREB transcriptional activity by $45 \mathrm{~min}$ (Figs. 3, 4), we next specifically tested the hypothesis that the MAPK activation observed following a single training trial (Fig. $5 a$, ASW) is necessary to establish the permissive ITI at 45 min during twotrial LTM induction. We restricted U0126 exposure to disrupt

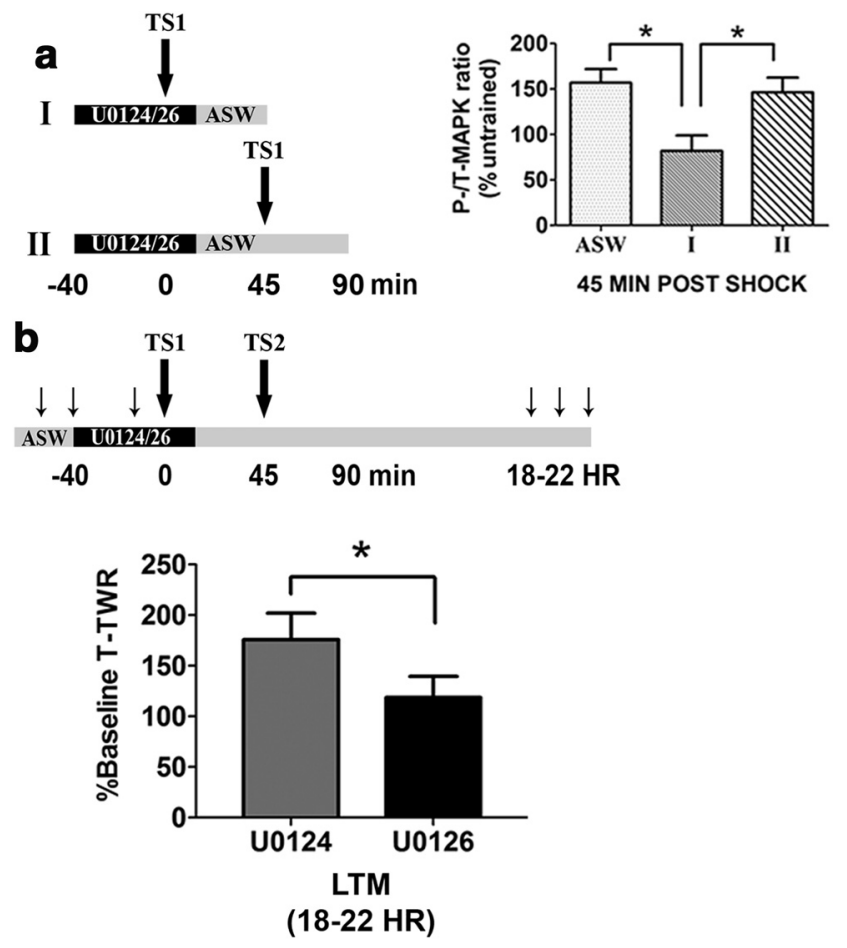

Figure 5. Trial 1 MAPK is necessary for the intertrial interaction during induction of LTM. $\boldsymbol{a}$, Experimental strategy to selectively disrupt MAPK activation during the initial training shock (ASW histogram), while leaving intact the potential for MAPK activation by the second shock during two-trial training. I, CNS exposure to U0126 for $40 \mathrm{~min}$ before, during and $15 \mathrm{~min}$ after the administration of a single training shock to behaving T-TWR preparations was sufficient to disrupt Trial 1 MAPK activation in tail SNs (ASW vs I in summary histogram, right). II, A 30 min drug washout following the same treatment in I (55 min U0126 exposure, no training), was sufficient to restore MEK activity as demonstrated by the ability of a single shock at this time point to activate MAPK at 45 min postshock. $\boldsymbol{b}$, The specific disruption of Trial 1-induced MAPK activation during two-trial learning prevents LTM formation. Asterisk indicates a significant difference in the between group comparison. Data are mean \pm SEM.

only MAPK activation by training Trial 1 , but not activation by subsequent training (Trial 2). U0124/U0126 was applied to the CNS of reduced T-TWR preparations 40 min before training, during the establishment of baseline responding, and remained until 15 min after Trial 1 (Fig. 5a). This treatment significantly disrupted Trial 1 MAPK activation observed at $45 \min (n=5$, $82 \pm 17 \%$ control; Fig. $5 a$, I). Additionally, the inhibition of MEK could be readily reversed before the temporal window for the second training shock at $45 \mathrm{~min}$, as evidenced by the restoration of MAPK activation when a single shock was administered to T-TWR preparations following $30 \mathrm{~min}$ of drug washout $(n=6$, $147 \pm 16 \%$ control, $p=0.044$; Fig. $5 a$,II). Thus, treatment with U0126 until 15 min post-training Trial 1, permits us to specifically test the requirement for MAPK activation by Trial 1 in twotrial LTM induction, without disturbing the ability of the second training shock (Trial 2) to activate MAPK. Using this experimental strategy (Fig. 5a), in control experiments we observed significant LTM at $18-22 \mathrm{~h}$ after training in the presence of U0124 $(n=$ $7,176 \pm 26 \%$ baseline T-TWR amplitude, $p=0.012$ paired $t$ test, Fig. 5b). However, LTM induction was significantly disrupted by the specific elimination of Trial 1 MAPK activation (U0126: $n=$ 7, $119 \pm 21 \%$ baseline, $p=0.658)$. These data establish that MAPK activity recruited by the initial training shock is required for the intertrial interaction during two-trial LTM induction. 


\section{Discussion}

A model summarizing our findings is shown in Figure 6. Two-trial LTM for sensitization of both the T-SWR (Philips et al., 2007) and the T-TWR (Fig. 1) shares a narrow permissive training interval at 45 min. This observation is consistent with the hypothesis that much of the pattern sensitivity during memory formation occurs within the common input pathway to both reflexes, the tail SNs. Brief treatment of the CNS with 5HT, which can substitute for sensitization training in the T-TWR (Walters et al., 1983a; Philips et al., 2011), was sufficient to mimic the training shock-induced delayed and restricted activation of MAPK observed in tail SNs at the 45 min permissive window for two-trial LTM induction (Philips et al., 2007). Unexpectedly, we found that MAPK activation induced by Trial 1 required protein synthesis which may, in part, explain the temporal delay in MAPK activation observed during training. We also found that Trial 1 MAPK translocated to the nucleus of tail SNs by $45 \mathrm{~min}$ and established a unique and transient molecular context, which included activation of the CREB kinase p90rsk and increased expression of the CREB target and IEG, $A p C / E B P$. Finally, we established the behavioral relevance of the Trial 1 MAPKdependent "molecular context," which was required for the intertrial interaction during two-trial LTM induction. Thus we demonstrate an essential requirement for MAPK activity in the intertrial interactions during pattern-sensitive LTM formation and provide a testable model in many other systems that the recruitment and nuclear signaling of MAPK (perhaps surprisingly early) during learning trials may ultimately determine effective training intervals during memory formation.

The kinetics of Trial 1 MAPK activation establish the two-trial training interval that is effective in LTM induction

The two-trial training interval for LTM induction in both the T-SWR and the T-TWR is surprisingly narrow, restricted to $45 \mathrm{~min}$ (but not $15 \mathrm{~min}$ or $1 \mathrm{~h}$ ) following an initial training shock (Fig. 1; Sutton et al., 2002; Philips et al., 2007). Given that MAPK activity is a necessary component of the intertrial signaling during two-trial learning (Fig. 5), and is not activated in the somatic compartment of tail SNs of the reflex circuit until $45 \mathrm{~min}$, the delay in MAPK activation may be sufficient to explain the failure of the 15 min training interval to induce LTM. It is not until $45 \mathrm{~min}$, when the MAPK-dependent molecular context in tail SNs has been established, that a second training shock can support LTM formation (Fig. 6). Strikingly, following both tail shock (Philips et al., 2007) and 5HT treatment (Fig. 2), single-trial MAPK activation is inactivated by $1 \mathrm{~h}$. This

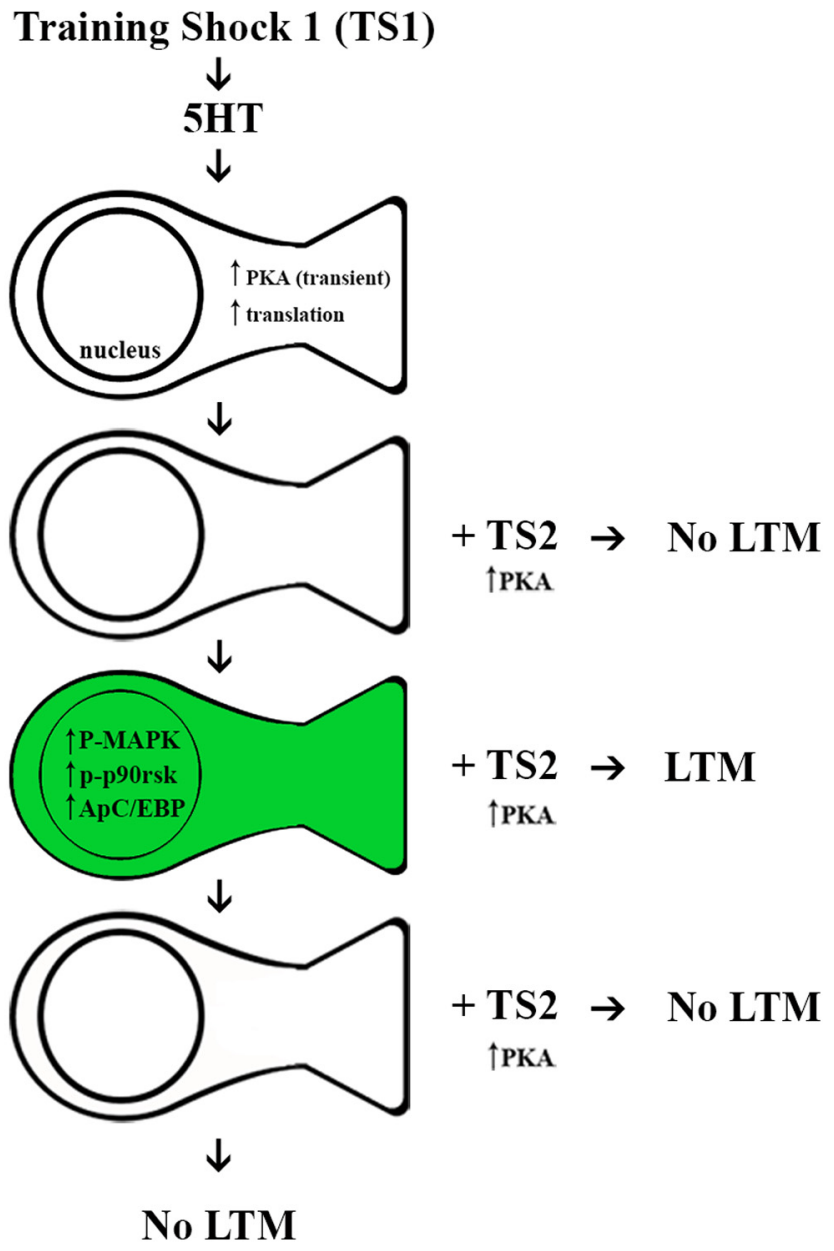

Figure 6. A model depicting how MAPK establishes a molecular context that defines effective training intervals for LTM. A single training shock (TS) releases 5HT onto tail SNs and sensorimotor synapses (Marinesco and Carew, 2002; Philips et al., 2011). 5HT acts at SN membranes through a receptor-coupled adenylate cyclase to increase levels of CAMP and activate PKA in sensory neuron somata and synaptic terminals (Bacskai et al., 1993; Muller and Carew, 1998). cAMP/PKA activation is transient and is inactivated within 15 min following TS. MAPK activation by the same TS is delayed, and appears in the cell body and nucleus at 45 min, but not Trial 1 MAPK activity establishes a unique molecular context within tail SNs by $45 \mathrm{~min}$ that is required for two-trial LTM formation. By 45 min, MAPK has activated the CREB pathway as observed in the increased phosphorylation of the CREB kinase p90rsk and dependent molecular context is not sufficient for LTM and must interact with additional signaling from a second TS at 45 min to the rectional 5HT release, PKA activity and the PKA-dependent activation of the ApC/EBP/APAF complex which is sufficient to drive long-term synaptic facilitation at SN-MN synapses (Lee et al., 2006). The delayed onset of the MAPK-dependent (h) context may be sufficient to explain the failure of the short (15 min) training interval to support LTM formation. Longe (1 h) training intervals may similarly fail to support LTM induction because the required MAPK signaling and MAPK-dependent gene expression has ended by $1 \mathrm{~h}$.

rapid inactivation of MAPK, and of the MAPK-dependent recruitment of CREB kinase and $A p C / E B P$ expression, by $1 \mathrm{~h}$ may account for the failure of this longer training interval in two-trial LTM induction (Sutton et al., 2002; Philips et al., 2007). Importantly, the kinetics for the activation of MAPK in the cell body and nuclei of tail SNs following an initial training experience appears to determine the delayed ( $45 \mathrm{~min}$ ) two-trial training interval for LTM induction and is consistent with the correlations of intertrial MAPK activation to successful training intervals during LTM formation in other systems (Pagani et al., 2009).

We studied possible mechanisms for the activation of Trial 1 MAPK and found that it required protein synthesis (Fig. 2). Intriguingly, rapid rates of protein synthesis and degradation have recently been implicated in the neuronal processing underlying 
synaptic facilitation of $\mathrm{SN}-\mathrm{MN}$ synapses that develops across repeated spaced, but not massed, applications of 5HT (Naqib et al., 2011). The sustained activation of nuclear MAPK following five repeated spaced training shocks or spaced pulses of 5HT (Sharma et al., 2003) appears to be initiated in the presynaptic terminals of $\mathrm{SN}-\mathrm{MN}$ synapses and requires the synthesis and local synaptic signaling of the neurotrophin-like peptide sensorin ( $\mathrm{Hu}$ et al., 2004; Wang et al., 2009). Given (1) that Trial 1 MAPK activation requires protein synthesis and (2) that protein synthesis is increased within minutes following brief 5HT treatment to isolated SN neurites in culture (Casadio et al., 1999; Si et al., 2003), an intriguing possibility is that a sensorin-dependent signal in the synapse may be upstream of Trial 1 MAPK activation. Consistent with this idea, in a preliminary investigation we observed that 5HT-induced MAPK activation at $45 \mathrm{~min}$ could be disrupted with a blocking antibody against sensorin that antagonizes the autocrine signaling of sensorin at tail SNs. Collectively, the data suggest that the timing of the MAPK-dependent two-trial training interval is a reflection of the dependence of Trial 1 MAPK activation on new protein synthesis (perhaps the local synaptic translation of sensorin).

Finally, the recruitment of a second, delayed phase of MAPK activation following training has been shown to be important for the development of long-term memory following both multipletrial spaced (Atkins et al., 1998; Shobe et al., 2005) and single-trial (Cammarota et al., 2000; Michel et al., 2011) training patterns. In Aplysia, we previously reported that the delayed MAPK activation that follows spaced training requires protein synthesis, but not transcription (Shobe et al., 2005 and unpublished observations), similar to the present observations for intertrial MAPK activation. Both the extent to which the mechanisms responsible for the delayed activation of MAPK in these two phases of memory formation are similar or different, as well as the potential relationship of these two phases, remain important questions for further study. Importantly, the delayed recruitment of MAPK during learning (i.e., following single training trials that are subthreshold for LTM induction) has now been described in several systems (Philips et al., 2007; Pagani et al., 2009), and although it has received less attention than post-training MAPK signaling, it appears to be essential in determining effective training intervals across several species.

\section{CREB and $A p C / E B P$ are recruited as part of a MAPK-dependent molecular context important for intertrial signaling during LTM formation}

The temporal correlation between the appearance of activated MAPK in the cell bodies of tail SNs (cytoplasm and nucleus) and the permissive two-trial training interval suggests an important role for MAPK activity in this specific cellular compartment for intertrial signaling during LTM induction. In support of this notion, we found that Trial 1 MAPK established a molecular context of CREB signaling that included $A p C / E B P$ induction (Fig. 4), an essential requirement for LTM formation. Given that a single training shock is not sufficient for LTM induction, the recruitment of nuclear MAPK translocation, CREB kinase and $A p C / E B P$ is quite surprising, and provides initial experimental evidence suggesting novel roles for CREB and $A p C / E B P$ in the intertrial signaling important for LTM formation over spaced training trials. Consistent with this notion, Parsons and Davis (2012) recently reported the recruitment at $1 \mathrm{~h}$ of a transient CREB phosphorylation in the amygdala of rats given a single training trial which, in itself, was subthreshold for the induction of STM and LTM for a form of fear memory. Additionally, Silva and colleagues (1998) previously suggested that minimal effective spaced training intervals may be determined by the time required to recruit CREB and to complete a round of CREB-dependent gene expression before subsequent training trials could effectively recruit additional rounds of transcription. Finally, our findings are also consistent with the intriguing hypothesis, that since many immediate early genes (IEGs) code for transcription factors, they may be recruited during learning as agents of metaplasticity (Clayton, 2000; Kaczmarek, 2000; Guzowski, 2002). From this perspective, IEG induction following an initial experience would serve to "prime" the transcriptional response during a subsequent experience to support the transcriptional requirements of LTM induction (Guzowski, 2002). Consistent with this notion, the overexpression of $A p C / E B P$ in Aplysia SNs is not sufficient to support the induction of long-term facilitation at sensorimotor synapses, but must be combined with a brief $5 \mathrm{HT}$ exposure (Lee et al., 2001). Indeed, a MAPK-dependent $A p C / E B P$ induction by Trial 1 may interact with 5HT release following Trial 2 to support two-trial LTM formation. Importantly, the role of IEGs in intertrial signaling can now be directly examined using the present two-trial training paradigm we have developed.

\section{Two-trial training patterns provide a unique opportunity to study the spacing effect in LTM formation}

At a broader level, this work demonstrates the unique advantages provided by simple training patterns for the study of the mechanisms underlying the temporal specificity of intertrial intervals during LTM formation. Since the pioneering work of Ebbinghaus (1885) it has been widely appreciated that the spacing of repeated training trials benefits memory retention. But the mechanisms that determine the benefit of specific training intervals are completely unknown. In part, this is due to the common practice of training with multiple spaced training trials, which makes it inherently difficult to determine the contribution of each individual trial to the development of the final memory. A recent seminal study by Zhang et al. (2012) used a computer model, which incorporated basic knowledge of the kinetics of PKA and MAPK activation following a single training trial in the tail SNs of Aplysia, to predict effective five-trial spaced training patterns that would result in the maximal coincident recruitment of PKA and MAPK signaling. Computer simulations, followed by experimental validation, identified "enhanced" training patterns over the standard regularly spaced protocol for the induction of longterm synaptic facilitation and LTM that were surprisingly nonintuitive and shared in common the feature that they were not regularly spaced in time (Zhang et al., 2012). Together with recent findings that just two appropriately spaced training trials can support LTM induction in Aplysia (Philips et al., 2007) and rats (Parsons and Davis, 2012), we suggest that an optimal strategy for understanding how spaced experiences interact to support LTM induction is to begin with two simple questions: First, what signaling is established by an initial experience, and second, in what temporal window(s) can subsequent experiences build upon this signaling to maximize the induction of LTM? These questions can be most directly explored in the analysis of LTM induction across just two spaced experiences. During two-trial training the contribution of each trial to the induction of memory can be easily understood: the initial experience (Trial 1) recruits signaling events that must interact with a subsequent experience (Trial 2) provided within a temporally bounded window to establish LTM.

In Aplysia, the simplest training interval for LTM for sensitization is defined in part through the temporally restricted re- 
cruitment of MAPK by an initial experience. However, we do not expect that $45 \mathrm{~min}$ will be the optimal training interval for twotrial memory induction in other systems or that this interval will even be optimal for other forms of learning in Aplysia. Rather, the optimal interval may be determined by kinetics for the recruitment of MAPK following a wide range of training stimuli which will have their own unique temporal constraints. Moreover, there are likely additional two-trial training intervals that will be revealed through a reexamination of many of the currently employed multiple trial protocols. As a striking example, Parsons and Davis (2012) recently re-examined multiple trial memory formation for fear-potentiated startle in rats and identified a remarkable two-trial training window that ranged from $1 \mathrm{~h}$ to several days. Finally, studies in humans have made clear that the determination of optimal training intervals for LTM formation depends heavily upon the retention interval examined (Donovan and Radosevich, 1999; Cepeda et al., 2006; Cepeda et al., 2008). Thus several factors influence the benefit of specific training intervals. Continued efforts to understand the molecular mechanisms which underlie the sensitivity to this wide range of training patterns should provide new insights into this fundamental feature of memory formation.

\section{References}

Ajay SM, Bhalla US (2004) A role for ERKII in synaptic pattern selectivity on the time-scale of minutes. Eur J Neurosci 20:2671-2680. CrossRef Medline

Alberini CM, Ghirardi M, Metz R, Kandel ER (1994) C/EBP is an immediate-early gene required for the consolidation of long-term facilitation in Aplysia. Cell 76:1099-1114. CrossRef Medline

Arthur JS, Fong AL, Dwyer JM, Davare M, Reese E, Obrietan K, Impey S (2004) Mitogen- and stress-activated protein kinase 1 mediates cAMP response element-binding protein phosphorylation and activation by neurotrophins. J Neurosci 24:4324-4332. CrossRef Medline

Atkins CM, Selcher JC, Petraitis JJ, Trzaskos JM, Sweatt JD (1998) The MAPK cascade is required for mammalian associative learning. Nat Neurosci 1:602-609. CrossRef Medline

Bacskai BJ, Hochner B, Mahaut-Smith M, Adams SR, Kaang BK, Kandel ER, Tsien RY (1993) Spatially resolved dynamics of cAMP and protein kinase A subunits in Aplysia sensory neurons. Science 260:222-226. CrossRef Medline

Brunelli M, Castellucci V, Kandel ER (1976) Synaptic facilitation and behavioral sensitization in Aplysia: possible role of serotonin and cyclic AMP. Science 194:1178-1181. CrossRef Medline

Cammarota M, Bevilaqua LR, Ardenghi P, Paratcha G, Levi de Stein M, Izquierdo I, Medina JH (2000) Learning-associated activation of nuclear MAPK, CREB and Elk-1, along with Fos production, in the rat hippocampus after a one-trial avoidance learning: abolition by NMDA receptor blockade. Brain Res Mol Brain Res 76:36-46. CrossRef Medline

Casadio A, Martin KC, Giustetto M, Zhu H, Chen M, Bartsch D, Bailey CH, Kandel ER (1999) A transient, neuron-wide form of CREB-mediated long-term facilitation can be stabilized at specific synapses by local protein synthesis. Cell 99:221-237. CrossRef Medline

Cepeda NJ, Pashler H, Vul E, Wixted JT, Rohrer D (2006) Distributed practice in verbal recall tasks: A review and quantitative synthesis. Psychol Bull 132:354-380. CrossRef Medline

Cepeda NJ, Vul E, Rohrer D, Wixted JT, Pashler H (2008) Spacing effects in learning: a temporal ridgeline of optimal retention. Psychol Sci 19:10951102. CrossRef Medline

Clayton DF (2000) The genomic action potential. Neurobiol Learn Mem 74:185-216. CrossRef Medline

Dalby KN, Morrice N, Caudwell FB, Avruch J, Cohen P (1998) Identification of regulatory phosphorylation sites in mitogen-activated protein kinase (MAPK)-activated protein kinase-1a/p90rsk that are inducible by MAPK. J Biol Chem 273:1496-1505. CrossRef Medline

Dixon WJ, Tukey JW (1968) Approximate behavior of distribution of winsorized T (Trimming/Winsorization 2). Technometrics 10:83-98. CrossRef

Donovan JJ, Radosevich DJ (1999) A meta-analytic review of the distribu- tion of practice effect: Now you see it, now you don't. J Appl Psychol 84:795-805. CrossRef

Ebbinghaus HE (1885) Memory: A Contribution to Experimental Psychology. New York: Dover.

Guzowski JF (2002) Insights into immediate-early gene function in hippocampal memory consolidation using antisense oligonucleotide and fluorescent imaging approaches. Hippocampus 12:86-104. CrossRef Medline

Guzowski JF, McGaugh JL (1997) Antisense oligodeoxynucleotidemediated disruption of hippocampal cAMP response element binding protein levels impairs consolidation of memory for water maze training. Proc Natl Acad Sci U S A 94:2693-2698. CrossRef Medline

Hu JY, Glickman L, Wu F, Schacher S (2004) Serotonin regulates the secretion and autocrine action of a neuropeptide to activate MAPK required for long-term facilitation in Aplysia. Neuron 43:373-385. CrossRef Medline

Hu JY, Wu F, Schacher S (2006) Two signaling pathways regulate the expression and secretion of a neuropeptide required for long-term facilitation in Aplysia. J Neurosci 26:1026-1035. CrossRef Medline

Kaczmarek L (2000) Gene expression in learning processes. Acta Neurobiol Exp (Wars) 60:419-424. Medline

Lee JA, Kim HK, Kim KH, Han JH, Lee YS, Lim CS, Chang DJ, Kubo T, Kaang BK (2001) Overexpression of and RNA interference with the CCAAT enhancer-binding protein on long-term facilitation of Aplysia sensory to motor synapses. Learn Mem 8:220-226. CrossRef Medline

Lee JA, Lee SH, Lee C, Chang DJ, Lee Y, Kim H, Cheang YH, Ko HG, Lee YS, Jun H, Bartsch D, Kandel ER, Kaang BK (2006) PKA-activated ApAFApC/EBP heterodimer is a key downstream effector of ApCREB and is necessary and sufficient for the consolidation of long-term facilitation. J Cell Biology 174:827-838. CrossRef Medline

Lee YS, Bailey CH, Kandel ER, Kaang BK (2008) Transcriptional regulation of long-term memory in the marine snail Aplysia. Mol Brain 1:3. CrossRef Medline

Marinesco S, Carew TJ (2002) Serotonin release evoked by tail nerve stimulation in the CNS of Aplysia: characterization and relationship to heterosynaptic plasticity. J Neurosci 22:2299-2312. Medline

Mauelshagen J, Parker GR, Carew TJ (1996) Dynamics of induction and expression of long-term synaptic facilitation in Aplysia. J Neurosci 16: 7099-7108. Medline

Michel M, Green CL, Eskin A, Lyons LC (2011) PKG-mediated MAPK signaling is necessary for long-term operant memory in Aplysia. Learn Mem 18:108-117. CrossRef Medline

Müller U, Carew TJ (1998) Serotonin induces temporally and mechanistically distinct phases of persistent PKA activity in Aplysia sensory neurons. Neuron 21:1423-1434. CrossRef Medline

Naqib F, Farah CA, Pack CC, Sossin WS (2011) The rates of protein synthesis and degradation account for the differential response of neurons to spaced and massed training protocols. PLoS Comput Biol 7:e1002324. CrossRef Medline

Pagani MR, Oishi K, Gelb BD, Zhong Y (2009) The phosphatase SHP2 regulates the spacing effect for long-term memory induction. Cell 139:186198. CrossRef Medline

Parsons RG, Davis M (2012) A metaplasticity-like mechanism supports the selection of fear memories: role of protein kinase a in the amygdala. J Neurosci 32:7843-7851. CrossRef Medline

Philips GT, Tzvetkova EI, Carew TJ (2007) Transient mitogen-activated protein kinase activation is confined to a narrow temporal window required for the induction of two-trial long-term memory in Aplysia. J Neurosci 27:13701-13705. CrossRef Medline

Philips GT, Sherff CM, Menges SA, Carew TJ (2011) The tail-elicited tail withdrawal reflex of Aplysia is mediated centrally at tail sensory-motor synapses and exhibits sensitization across multiple temporal domains. Learn Mem 18:272-282. CrossRef Medline

Pinsker HM, Hening WA, Carew TJ, Kandel ER (1973) Long-term sensitization of a defensive withdrawal reflex in Aplysia. Science 182:1039-1042. CrossRef Medline

Romeo Y, Zhang X, Roux PP (2012) Regulation and function of the RSK family of protein kinases. Biochem J 441:553-569. CrossRef Medline

Sharma SK, Carew TJ (2004) The roles of MAPK cascades in synaptic plasticity and memory in Aplysia: facilitatory effects and inhibitory constraints. Learn Mem 11:373-378. CrossRef Medline

Sharma SK, Sherff CM, Shobe J, Bagnall MW, Sutton MA, Carew TJ (2003) 
Differential role of mitogen-activated protein kinase in three distinct phases of memory for sensitization in Aplysia. J Neurosci 23:3899-3907. Medline

Sherff CM, Carew TJ (2004) Parallel somatic and synaptic processing in the induction of intermediate-term and long-term synaptic facilitation in Aplysia. Proc Natl Acad Sci U S A 101:7463-7468. CrossRef Medline

Shobe JL, Sharma SK, Carew TJ (2005) Long-term memory for sensitization in Aplysia requires sustained ERK activity. Soc Neurosci Abstr 31:540.10.

Si K, Giustetto M, Etkin A, Hsu R, Janisiewicz AM, Miniaci MC, Kim JH, Zhu H, Kandel ER (2003) A neuronal isoform of CPEB regulates local protein synthesis and stabilizes synapse-specific long-term facilitation in Aplysia. Cell 115:893-904. CrossRef Medline

Silva AJ, Kogan JH, Frankland PW, Kida S (1998) CREB and memory. Annu Rev Neurosci 21:127-148. CrossRef Medline

Sindreu CB, Scheiner ZS, Storm DR (2007) $\mathrm{Ca}^{2+}$-stimulated adenylyl cyclases regulate ERK-dependent activation of MSK1 during fear conditioning. Neuron 53:79-89. CrossRef Medline

Sutton MA, Masters SE, Bagnall MW, Carew TJ (2001) Molecular mechanisms underlying a unique intermediate phase of memory in Aplysia. Neuron 31:143-154. CrossRef Medline

Sutton MA, Ide J, Masters SE, Carew TJ (2002) Interaction between amount and pattern of training in the induction of intermediate- and long-term memory for sensitization in Aplysia. Learn Mem 9:29-40. CrossRef Medline

Taubenfeld SM, Milekic MH, Monti B, Alberini CM (2001) The consolidation of new but not reactivated memory requires hippocampal C/EBPbeta. Nat Neurosci 4:813-818. CrossRef Medline
Tidyman WE, Rauen KA (2009) The RASopathies: developmental syndromes of Ras/MAPK pathway dysregulation. Curr Opin Genet Dev 19: 230-236. CrossRef Medline

Turjanski AG, Vaqué JP, Gutkind JS (2007) MAP kinases and the control of nuclear events. Oncogene 26:3240-3253. CrossRef Medline

Walters ET, Byrne JH, Carew TJ, Kandel ER (1983a) Mechanoafferent neurons innervating tail of Aplysia. II. Modulation by sensitizing stimulation. J Neurophysiol 50:1543-1559. Medline

Walters ET, Byrne JH, Carew TJ, Kandel ER (1983b) Mechanoafferent neurons innervating tail of Aplysia. I. Response properties and synaptic connections. J Neurophysiol 50:1522-1542. Medline

Walters ET, Bodnarova M, Billy AJ, Dulin MF, Díaz-Ríos M, Miller MW, Moroz LL (2004) Somatotopic organization and functional properties of mechanosensory neurons expressing sensorin-A mRNA in Aplysia californica. J Comp Neurol 471:219-240. CrossRef Medline

Wang DO, Kim SM, Zhao Y, Hwang H, Miura SK, Sossin WS, Martin KC (2009) Synapse- and stimulus-specific local translation during longterm neuronal plasticity. Science 324:1536-1540. CrossRef Medline

Yin JC, Wallach JS, Del Vecchio M, Wilder EL, Zhou H, Quinn WG, Tully T (1994) Induction of a dominant negative CREB transgene specifically blocks long-term memory in Drosophila. Cell 79:49-58. CrossRef Medline

Zhang Y, Liu RY, Heberton GA, Smolen P, Baxter DA, Cleary LJ, Byrne JH (2012) Computational design of enhanced learning protocols. Nat Neurosci 15:294-297. CrossRef Medline 